\title{
Is rumen development in newborn calves affected by different liquid feeds and small intestine development?
}

\author{
P. Górka, ${ }^{\star 1}$ Z. M. Kowalski, ${ }^{\star}$ P. Pietrzak,† A. Kotunia,ł W. Jagusiak,§ and R. Zabielski† \\ ${ }^{*}$ Department of Animal Nutrition and Feed Management, University of Agriculture in Krakow, 31-121 Krakow, Poland \\ †Department of Physiological Sciences, Faculty of Veterinary Medicine, Warsaw University of Life Sciences, 02-766 Warsaw, Poland \\ $\ddagger$ The Kielanowski Institute of Animal Physiology and Nutrition, Polish Academy of Sciences, 05-110 Jablonna, Poland \\ §Department of Genetics and Animal Breeding, University of Agriculture in Krakow, 31-121 Krakow, Poland
}

\begin{abstract}
The objective of the study was to determine the effect of different liquid feeds on calf small intestine and rumen development. Twenty-one bull calves $(5 \pm$ $1 \mathrm{~d}$ old) were randomly allocated to 3 groups and fed whole milk (WM), milk replacer (MR; $22 \% \mathrm{CP}$ and $17.5 \%$ fat), or MR supplemented with sodium butyrate $(\mathrm{MR}+\mathrm{SB} ; 0.3 \%$ as fed). Liquid feed dry matter intake was equal between treatments and amounted to $1 \%$ of $\mathrm{BW}$ at the beginning of the trial. Starter diet was offered ad libitum. Animals were slaughtered at $26( \pm 1)$ d of age. Calves fed WM had higher average daily gain in the whole trial and higher starter diet dry matter intake between d 15 to 21 of the trial as compared with calves fed MR and MR+SB. Calves fed MR lost on average $1.4 \mathrm{~kg}$ of $\mathrm{BW}$ within first $14 \mathrm{~d}$ of the trial and their BW tended to be lower at d 7, 14, and 21 of the study as compared with calves fed MR+SB. The empty jejunum and ileum weight, crypt depth, mitotic index in the middle jejunum were higher, and apoptotic index tended to be lower in calves fed WM as compared with calves fed MR and MR+SB. Calves fed WM also had higher aminopeptidase $\mathrm{N}$ activity in the middle jejunum and tended to have higher maltase activity in the distal jejunum as compared with calves fed MR and $\mathrm{MR}+\mathrm{SB}$. The mitotic index was higher and apoptotic index was lower in the middle jejunum, and aminopeptidase A activity tended to be higher in the distal jejunum of calves fed $\mathrm{MR}+\mathrm{SB}$ as compared with those fed MR. Calves fed WM had greater papillae length and width, and tended to have greater muscle layer thickness as compared with calves fed MR and MR+SB. Reticulorumen weight, reticulorumen weight expressed as percent of whole stomach weight, and papillae length and width were higher in calves fed $\mathrm{MR}+\mathrm{SB}$ as compared with those fed MR. Additionally, calves fed WM had higher plasma glucose and urea in the whole trial
\end{abstract}

Received June 2, 2010.

Accepted February 3, 2011.

${ }^{1}$ Corresponding author: p.gorka@ur.krakow.pl period as compared with calves fed $\mathrm{MR}$ and $\mathrm{MR}+\mathrm{SB}$, and plasma glucose was higher in calves fed $\mathrm{MR}+\mathrm{SB}$ as compared with those fed MR. Significant positive Pearson correlations were found between small intestine and reticulorumen weights as well as between activity of brush border lactase, maltase, aminopeptidase A, and aminopeptidase $\mathrm{N}$ and reticulorumen weight. Different liquid feeds affect small intestine development, animal growth, solid feed intake and metabolic status of calves and this effect can indirectly influence the development of forestomachs.

Key words: gastrointestinal tract, whole milk, milk replacer, sodium butyrate

\section{INTRODUCTION}

Feeding newborn calves a limited amount of whole milk (WM) or milk replacer (MR) and free-choice starter mixture is a common practice on dairy farms in many countries, including Poland. Such a feeding strategy substantially speeds up rumen development and decreases the weaning age of calves, and in consequence, significantly decreases costs of rearing calves (Baldwin et al., 2004). If calves are early weaned (3-4 weeks of age) special attention should be paid to the composition and structure of solid feed offered, because it is the main stimulator of rumen development (Tamate et al., 1962; Žitňan et al., 1998). Therefore, many attempts to optimize solid feed composition for early weaned calves are still carried out (Lesmeister and Heinrichs, 2004; Khan et al., 2007b; Hill et al., 2008).

On the other hand, it is widely accepted to feed dairy calves MR instead of WM. It is well known that MR may slow down calf small intestine development (Seegraber and Morrill, 1986; Blättler et al., 2001), especially when MR contains plant proteins (Seegraber and Morrill, 1986; Montagne et al., 1999; Drackley et al., 2006), popularly used as cheaper substitutes of milk proteins. Liquid feed (WM or MR) is a sole source of nutrients for newborn calves until regular solid feed intake starts and the small intestine is the main site of liquid feed digestion. If small intestine development 
affects liquid feed digestion and nutrient absorption, and consequently, calf growth and health in the first weeks of life, it may also affect solid feed intake and, indirectly, rumen development. Liquid feed type and composition may also influence plasma concentration of insulin, IGF-1 and other growth factors (Baumrucker and Blum, 1994; Zabielski et al., 1998; Kuhne et al., 2000), which play an important role in stimulation of rumen epithelial cell proliferation (Sakata et al., 1980; Zitnan et al., 2005). Because feeding calves MR slows down small intestine development, it may also impair rumen development. However, to our best knowledge, the detailed relationship between small intestine development and rumen development has not been documented so far.

Supplementation of sodium butyrate (SB) in MR was shown to have a positive effect on small intestine development in calves (Pietrzak et al., 2008; Guilloteau et al., 2009). It stimulated intestinal cell proliferation, villus growth, and digestive enzyme activity and, as a result, positively affected calf performance and health (Guilloteau et al., 2004, 2009; Hill et al., 2007). Although dietary addition of SB in MR on small intestine development has been investigated, its effect on forestomach development has not been determined so far.

The aim of a present study was to determine the effect of different liquid feeds (WM, MR, and MR with SB) on small intestine and rumen development in calves. We hypothesized that feeding calves MR instead of WM would slow down small intestine development and, indirectly, rumen development, and addition of SB to MR would accelerate it.

\section{MATERIALS AND METHODS}

\section{Animals and Diets}

The animal study protocol was approved by the Local Ethics Committee before the onset of the trial. The trial was conducted at a dairy farm (Top Farms Głubczyce Sp. z o. o.) located in Southern Poland. Twenty-one clinically healthy male calves (Holstein or Holstein $x$ Limousine) of mean age $5( \pm 1)$ d were randomly allocated to one of 3 experimental groups ( 7 calves per group) and fed WM or MR or MR supplemented with $\mathrm{SB}$ (MR+SB). The MR+SB contained $0.3 \%$ (as fed) crystalline SB (VetAgro, Reggio Emilia, Italy) that was introduced into the MR by the manufacturer. The number of Holstein $\times$ Limousine animals ranged between 2 to 4 in each group and the effect of breed was incorporated into statistical models to balance data. For most of the analyzed parameters this effect was insignificant.
Before the onset of the trial, up to d 2 of life, the calves were fed $2.5 \mathrm{~L}$ of colostrum and transition milk, and then $2.5 \mathrm{~L}$ of $\mathrm{WM}$ given twice per day, without access to solid feeds. First colostrum was fed within the first $2 \mathrm{~h}$ of life. During the study, calves were kept in a ventilated barn in individual pens $(1.5 \times 1.2 \mathrm{~m})$ with a rubber floor covered with sawdust. Each calf was in the trial over a period of $21 \mathrm{~d}$, until the age of $26( \pm 1) \mathrm{d}$, when slaughtered.

The animals were fed individually. Whole milk was delivered from the local dairy farm, stored at $4^{\circ} \mathrm{C}$, and heated to 38 to $40^{\circ} \mathrm{C}$ before feeding. The $\mathrm{MR}$ or $\mathrm{MR}+\mathrm{SB}$ powders (Primolac; Polmass S.A., Bydgoszcz, Poland) were mixed with warm water $\left(38-40^{\circ} \mathrm{C}\right)$ in the ratio of powder-to-water of 1 to 9 . Sixty percent of milk protein in the $\mathrm{MR}$ and $\mathrm{MR}+\mathrm{SB}$ was replaced by soy protein concentrate. The soy protein concentrate was used as a component of MR to ensure slower small intestine development in calves fed MR. Liquid feeds were offered twice per day from a bucket with a teat, which ensured esophageal groove closure and no forestomach growth stimulation by SB supplementation in MR. Liquid feeds were offered always at the same time $(0800$ and $1500 \mathrm{~h}$ ). Liquid feed was introduced to the calf diet gradually, within the first $3 \mathrm{~d}$ of the trial, beginning at $50 \%$ of its target volume. Refusals of liquid feeds were recorded daily.

Liquid feed DMI was constant during the whole experimental period and amounted to $1 \%$ of $\mathrm{BW}$ of the calf at the start of the trial. To ensure equal liquid feed DMI between calves fed WM and MR, DM content in WM was monitored. At the beginning of the trial, based on the WM composition analysis carried out before the onset of the trial, the DM content in this liquid feed was set at $12 \%$. Thereafter, WM was sampled for DM determination weekly. DM in offered milk was similar for each sampled period and averaged $11.8 \%$ (Table 1).

Commercial pelleted starter mixture (KCJ; Polmass S.A.; 37-38\% CP in DM) was blended with whole corn grain $(50 / 50 ; \mathrm{wt} / \mathrm{wt})$ and offered ad libitum as a starter diet (StDt; 24.5 and $15.1 \%$ of CP and NDF in DM, respectively) once daily, after morning liquid feeding $(0900 \mathrm{~h})$, beginning on the first day of the study. Refusals of StDt were collected daily and samples from each calf were divided by sieving into the starter mixture and whole corn grain, for calculation of $\mathrm{CP}$ and $\mathrm{ME}$ intake.

Samples of WM, MR, MR+SB, starter mixture, and corn grain were collected weekly. They were then pooled and analyzed for DM, ash, CP, crude fat, crude fiber, $\mathrm{NDF}$, and ADF concentration using standard procedures (AOAC, 2000), and for starch content (Faisant et 
GÓRKA ET AL.

Table 1. Composition of experimental feeds (on DM basis)

\begin{tabular}{|c|c|c|c|c|c|c|}
\hline \multirow[b]{2}{*}{ Item } & \multicolumn{3}{|c|}{ Liquid feed $^{1}$} & \multicolumn{3}{|c|}{ Solid feed ${ }^{2}$} \\
\hline & WM & MR & $\mathrm{MR}+\mathrm{SB}$ & $\mathrm{SM}$ & $\mathrm{C}$ & $\mathrm{StDt}^{3}$ \\
\hline $\mathrm{DM}(\%)$ & 11.8 & 94.1 & 93.5 & 88.6 & 87.7 & 87.2 \\
\hline $\mathrm{CP}(\%)$ & 28.9 & 22.3 & 21.5 & 38.1 & 10.8 & 24.5 \\
\hline Crude fat $(\%)$ & 23.8 & 17.2 & 17.8 & 1.6 & 5.1 & 3.4 \\
\hline Crude fiber (\%) & $\mathrm{ND}^{4}$ & 0.1 & 0.1 & 6.6 & 1.9 & 4.3 \\
\hline $\operatorname{Ash}(\%)$ & 8.1 & 10.2 & 10.6 & 14.6 & 1.4 & 8.0 \\
\hline Lactose $^{5}(\%)$ & 39.2 & 49.8 & 50.4 & & & \\
\hline $\mathrm{N}$-free extractives ${ }^{6}(\%)$ & & & & 45.8 & 82.7 & 64.3 \\
\hline Starch $(\%)$ & & & & 10.9 & 67.0 & 39.0 \\
\hline $\operatorname{NDF}(\%)$ & & & & 19.2 & 11.0 & 15.1 \\
\hline $\mathrm{ADF}(\%)$ & & & & 10.0 & 5.1 & 7.6 \\
\hline $\mathrm{ME}^{7}$ (Mcal) & 5.0 & 4.5 & 4.6 & 3.0 & 3.3 & 3.2 \\
\hline
\end{tabular}

${ }^{1} \mathrm{WM}=$ whole milk; $\mathrm{MR}=$ milk replacer (Primolac, Polmass S.A., Bydgoszcz, Poland; $45 \%$ dried whey, $30 \%$ fat concentrate, $24 \%$ soy protein concentrate, $1 \%$ vitamin/mineral premix); $\mathrm{MR}+\mathrm{SB}=$ milk replacer containing $0.3 \%$ of sodium butyrate (VetAgro, Reggio Emilia, Italy) as fed.

${ }^{2} \mathrm{SM}=$ starter mixture (KCJ, Polmass S.A., Bydgoszcz, Poland; 60\% soybean meal, 10\% rapeseed meal, $15 \%$ wheat bran, $10 \%$ malt sprout, $4 \%$ yeasts, $1 \%$ vitamin/mineral premix); $\mathrm{C}=$ whole corn grain; $\mathrm{StDt}=$ starter diet.

${ }^{3}$ StDt consisted of SM mixed with C (50/50; wt/wt).

${ }^{4}$ Not detected.

${ }^{5}$ Lactose $=100-\mathrm{CP}-$ crude fat - crude fiber - ash.

${ }^{6} \mathrm{~N}$-free extractives $=100-\mathrm{CP}-$ crude fat - crude ash.

${ }^{7}$ Calculated from NRC (2001).

al. 1995). Metabolizable energy content was calculated based on NRC (2001) equations.

\section{Measurements and Observations}

The calves were weighed on d 0 (initial weight), 7, 14, and 21 (final weight) of the trial. Fecal score, including fluidity (4-point scale: $1=$ normal, $4=$ diarrhea), consistency $(5$-point scale: $1=$ normal, $2=$ frothy, 3 $=$ mucous, $4=$ sticky, $5=$ hard constipation), and smell (3-point scale: $1=$ normal, 3 = disgusting) were determined daily according to Larson et al. (1977). Every abnormal health condition such as fever, bronchitis, as well as every veterinary treatment (antibiotic, electrolyte therapy) was documented. Calves with diarrhea were treated with a commercial electrolyte solution (Rehydrat; Biowet Puławy, Poland). Electrolyte therapy was initiated when fecal fluidity equaled 3 or 4 and antibiotic therapy was initiated when rectal temperature was $>39.5^{\circ} \mathrm{C}$.

\section{Blood Parameters}

Blood samples were taken from the jugular vein at the beginning of the trial, and then weekly, before morning liquid feeding. Tubes containing EDTA (VT-100 STK; $0.1 \mathrm{~mL}$ of EDTA, $0.47 \mathrm{~mL} / \mathrm{L}$; CML, Nemours, France) for plasma separation were used. Blood was centrifuged at $2,300 \times g$ for $10 \mathrm{~min}$ at $8^{\circ} \mathrm{C}$ and plasma was frozen and stored at $-20^{\circ} \mathrm{C}$ until further analysis. Plasma glucose, urea, and BHBA concentration were determined at a commercial laboratory (WDL, Gietrzwałd, Poland) using an automatic chemical analyzer (Hitachi 902; Hitachi, Tokyo, Japan). For plasma glucose and urea concentration determination, the BioSystems (Barcelona, Spain) kits were used, whereas for plasma BHBA concentration determination, the kits were provided from Diagnostic System Laboratories, Inc. (Sinsheim, Germany).

\section{Gastrointestinal Development Parameters}

At the end of the trial ( $26 \pm 1 \mathrm{~d}$ of age), all calves were killed by captive bolt stunning, and exsanguinated. On the day of slaughter, the liquid feed was not offered. The entire forestomachs, abomasum, and small intestine were dissected. Rumen fluid was sampled for

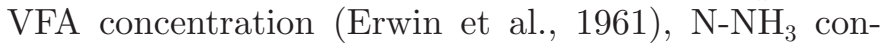
centration (Conway, 1962), and $\mathrm{pH}$ determination. The reticulorumen, omasum, and abomasum were separated, emptied, rinsed repeatedly with water, drained, and weighed individually. The duodenum, jejunum, and ileum were also separated, and all of these sections of the intestine were measured and weighed individually.

One square centimeter of the whole thickness samples from the left side of the cranial dorsal sac of the rumen and middle jejunum were fixed in $4 \%$ buffered formaldehyde for $5 \mathrm{~d}$ and then stored in ethanol. Then 
samples were embedded in paraffin, and serial histological sections were stained with hematoxylin and eosin for morphometry analysis under light microscope. Morphometry analysis involved papillae length and width, rumen muscle layer thickness, as well as villus length, crypt depth, mucosa thickness, and muscle layer thickness in the middle jejunum. Five to eight slides for each tissue sample were prepared. For each tissue sample, 30 measurements were done using an optical binocular microscope (Olympus BX 61; Olympus, Warszawa, Poland) coupled via a digital camera to a personal computer equipped with a cell^P (Olympus) software.

Whole-thickness middle jejunum samples were fixed in embedding medium, frozen, and labeled with a specific set of antibodies. For mitosis, anti-Ki-67-FITCconjugated (BD Biosciences Pharmingen, San Diego, CA), and for apoptosis, anti-Cpp32 (Dako, Glostrup, Denmark) and secondary Alexa Flour 488 chicken anti-rabbit antibodies (Molecular Probes, Inc., Eugene, OR) were used. Cell nuclei were stained with 7-aminoactinomycin D (Sigma-Aldrich Corporation, St. Louis, MO). Confocal microscopy (Olympus FV500; Olympus) and a Micro Imaging System (MicroImage 4.0; Olympus) were employed for in-tissue-cytometry analysis of mitotic and apoptotic indexes in the small intestinal epithelium (Godlewski et al., 2009).

Mucosa from proximal, middle, and distal jejunum and ileum was scraped by microscope slide, deep frozen and stored in $-80^{\circ} \mathrm{C}$. Then, the total protein content and activity of the main brush border enzymes in mucosa scrapings were determined. After thawing, $1 \mathrm{~g}$ of mucosa was homogenized with $5 \mathrm{~mL}$ of distilled water and centrifuged for $5 \mathrm{~min}$ at $1,000 \times \mathrm{g}$ at $4^{\circ} \mathrm{C}$. Total protein content was determined according to Hartree (1972). Lactase, maltase, and sucrase activities were determined according to Dahlqvist (1984) with minor modification. For aminopeptidase A and aminopeptidase $\mathrm{N}$ activity determination, L-glutamyl- $p$-nitroanilide and L-leucyl-p-nitroanilide (Bachem, Budendorf, Sweden), respectively (Maroux et al., 1973), and for dipeptidase IV activity L-glycyl-p-nitroanilide (Bachem) were used as a substrate (Nagatsu et al., 1976). Enzymatic activity is presented as enzymatic units. One enzymatic unit expresses $1 \mu \mathrm{mol}$ of glucose or $p$-nitroanilide released/ min of reaction at $37^{\circ} \mathrm{C}$.

\section{Statistical Analysis}

Data were analyzed as a completely randomized design. Repeated data over 1 subject were analyzed as repeated measures using the PROC MIXED statement of the SAS (2002), with calf as a random effect, and the effect of different liquid feeds and their interaction with time as a fixed effect (Littell et al., 1998). Data of DM,
$\mathrm{CP}$, and ME intake, and whole corn grain intake were averaged by week of the trial and then analyzed. The statistical model used for repeated measure analyses was

$$
Y_{c f t}=\mu+\alpha_{f}+\beta_{t}+(\alpha \beta)_{f t}+\gamma(\alpha)_{c f}+\delta_{c}+e_{c f t},
$$

where $Y_{c f t}=$ an observation value for BW, ADG, $\mathrm{DM}, \mathrm{CP}$, and ME intake, whole corn grain intake, and concentration of selected parameters in blood plasma taken from calf $c$ fed different liquid feed $f$ at time $t$; $\mu=$ overall mean for the population; $\alpha_{f}=$ fixed effect of liquid feed $f$, where $f=\mathrm{WM}, \mathrm{MR}$, or $\mathrm{MR}+\mathrm{SB} ; \beta_{t}$ $=$ fixed effect of time $t$, where $t=\mathrm{d} 0,7,14$, or 21 for BW and blood parameters or week of the trial (d 0 to $7, \mathrm{~d} 8$ to 14 , and d 15 to 21 ) for ADG, DM, CP, and ME intake, and whole corn grain intake; $(\alpha \beta)_{f t}=$ fixed interaction of effect of liquid feed $f$ and time $t$; $\gamma(\alpha)_{c f}=$ random effect of calf $c$ nested within different liquid feed $f ; \delta_{c}=$ fixed effect of calf breed, where breed $=$ Holstein or Holstein $\times$ Limousine; and $e_{c f t}=$ error associated with the measurement taken from calf $c$ fed different liquid feed $f$ at time $t$.

Average results for the whole trial period (d 0 to 21) for BW gain, ADG, DM, CP, and ME intake and whole corn grain intake, days with scours, days with antibiotic, and days with electrolyte therapies, as well as stomach and small intestine development parameters were subjected to ANOVA using PROC GLM (SAS, 2002). The statistical model used was

$$
Y_{c f}=\mu+\alpha_{f}+\delta_{c}+e_{c f}
$$

where $Y_{c f}=$ an observation value for average BW gain, ADG, DM, CP, and ME intake, whole corn grain intake, concentration of selected parameters in blood plasma, days with scours, days with antibiotic, and days with electrolyte therapies in the whole trial period, and stomach and small intestine development parameters taken from calf $c$ fed different liquid feed $f ; \mu=$ overall mean for the population; $\alpha_{f}=$ fixed effect of liquid feed $f$, where $f=\mathrm{WM}, \mathrm{MR}$, or $\mathrm{MR}+\mathrm{SB} ; \delta_{c}=$ fixed effect of calf breed, where breed $=$ Holstein or Holstein $\times$ Limousine; $e_{c f}=$ error associated with the measurement taken from calf $c$ fed liquid feed $f$.

Initial BW of calves and initial plasma glucose, urea, and BHBA concentration were used as covariates for ADG, plasma glucose, urea, and BHBA concentration statistical analyses, respectively. Final BW was used as a covariate for stomach and small intestine weights and stomach and small intestine compartment weights, and the mean StDt intake in the whole trial was taken as a covariate for parameters of rumen development. Furthermore, the effect of initial age of the calves $( \pm 1$ 
GÓRKA ET AL.

Table 2. Dry matter, CP, and ME intake by calves fed different liquid feeds

\begin{tabular}{|c|c|c|c|c|c|c|}
\hline \multirow[b]{2}{*}{ Item } & \multicolumn{3}{|c|}{ Liquid feed ${ }^{1}$} & \multirow[b]{2}{*}{$\mathrm{SE}$} & \multicolumn{2}{|c|}{ Contrast $^{2}$} \\
\hline & WM & MR & $\mathrm{MR}+\mathrm{SB}$ & & 1 & 2 \\
\hline \multicolumn{7}{|l|}{$\mathrm{DMI}^{3}(\mathrm{~g} / \mathrm{kg}$ of $\mathrm{BW})$} \\
\hline d 0 to 7 & 7.7 & 7.0 & 7.3 & 0.04 & NS & NS \\
\hline d 8 to 14 & 11.5 & 11.4 & 10.9 & 0.05 & NS & NS \\
\hline d 15 to 21 & 15.1 & 13.5 & 12.1 & 0.05 & 0.03 & NS \\
\hline In the whole trial & 10.1 & 10.3 & 9.7 & 0.26 & NS & NS \\
\hline \multicolumn{7}{|c|}{$\mathrm{CP}$ intake $^{3,4}(\mathrm{~g} / \mathrm{kg}$ of $\mathrm{BW})$} \\
\hline d 0 to 7 & 2.2 & 1.6 & 1.6 & 0.04 & 0.03 & NS \\
\hline d 8 to 14 & 3.3 & 2.6 & 2.5 & 0.05 & 0.01 & NS \\
\hline d 15 to 21 & 4.2 & 3.2 & 3.1 & 0.05 & $<0.01$ & NS \\
\hline In the whole trial & 3.0 & 2.4 & 2.3 & 0.10 & $<0.01$ & $\mathrm{NS}$ \\
\hline \multicolumn{7}{|c|}{$\operatorname{ME}$ intake ${ }^{3,4}\left(\right.$ Mcal $\times 10^{-3} / \mathrm{kg}$ of BW $)$} \\
\hline d 0 to 7 & 37.1 & 30.1 & 32.1 & 0.7 & 0.10 & NS \\
\hline d 8 to 14 & 52.6 & 47.3 & 47.8 & 0.5 & NS & NS \\
\hline d 15 to 21 & 63.4 & 54.0 & 54.7 & 0.4 & $<0.01$ & NS \\
\hline In the whole trial & 47.2 & 42.3 & 43.1 & 0.8 & 0.02 & NS \\
\hline
\end{tabular}

${ }^{1}$ Treatment: $\mathrm{WM}=$ whole milk; $\mathrm{MR}=$ milk replacer; $\mathrm{MR}+\mathrm{SB}=$ milk replacer containing $0.3 \%$ sodium butyrate.

${ }^{2} 1=\mathrm{WM}$ vs. $\mathrm{MR}$ and $\mathrm{MR}+\mathrm{SB} ; 2=\mathrm{MR}$ vs. $\mathrm{MR}+\mathrm{SB}$.

${ }^{3}$ Significant effect of liquid feed $(P<0.01)$.

${ }^{4}$ Significant effect of time $(P<0.01)$.

d) was tested as a fixed effect. It was not significant for all parameters $(P>0.05)$ and was removed from the model.

The scientific hypothesis was verified based on preplanned contrasts (WM vs. MR and $\mathrm{MR}+\mathrm{SB}$, MR vs. $\mathrm{MR}+\mathrm{SB})$. The ESTIMATE statement of the SAS was used for treatment comparisons at particular points of time in repeated measurements analysis and the CONTRAST statement of the SAS was used for the comparison of average results obtained in the whole trial and for stomach and small intestine development parameters. Significance was declared at $P<0.05$ and tendencies at $P<0.10$.

\section{RESULTS}

\section{Diet Composition}

Feed composition is presented in Table 1. The contents of $\mathrm{CP}$, crude fat, and ME were higher in WM as compared with $\mathrm{MR}$ and MR+SB. On the other hand, MR and MR+SB had higher lactose content and contained a detectable amount of fiber. The MR and $\mathrm{MR}+\mathrm{SB}$ were similar in composition. However, the $\mathrm{MR}+\mathrm{SB}$ had slightly higher crude fat and ME content and lower CP content as compared with MR.

\section{Calf Performance and Health}

Calves fed WM had higher DMI with liquid and solid feed $/ \mathrm{kg}$ of BW between d 15 to 21 of the trial $(P=0.03)$ as compared with calves fed $\mathrm{MR}$ and $\mathrm{MR}+\mathrm{SB}$ (Table
2). Overall, no differences in DMI were observed. Crude protein intake $/ \mathrm{kg}$ of $\mathrm{BW}$ in each week of the trial, as well as in the whole trial period, was higher $(P<0.05)$ in calves fed WM than in those fed $\mathrm{MR}$ and $\mathrm{MR}+\mathrm{SB}$. Calves fed WM also consumed more $(P<0.05) \mathrm{ME} /$ $\mathrm{kg}$ of BW with liquid and solid feed between d 15 to 21 and in the whole trial period, and tended to $(P=0.10)$ consume more $\mathrm{ME}$ with liquid and solid feed $/ \mathrm{kg}$ of $\mathrm{BW}$ between d 0 to 7 . No differences in DMI, CP, and ME/ $\mathrm{kg}$ of $\mathrm{BW}$ between calves fed $\mathrm{MR}$ and $\mathrm{MR}+\mathrm{SB}$ were found.

Calves fed WM gained more weight $(P<0.01)$ in the whole trial period than those fed MR and MR+SB (Table 3). The ADG of these calves was higher $(P<$ 0.01 ) between $\mathrm{d} 8$ to 14 of the trial and in the whole trial period as compared with those fed MR and MR+SB. Calves fed MR lost, on average, $1.4 \mathrm{~kg}$ of $\mathrm{BW}$ within the first $14 \mathrm{~d}$ of the trial and those fed $\mathrm{MR}+\mathrm{SB}$ tended to $(P<0.09)$ have higher ADG between d 0 to 7 of the trail and tended to $(P<0.10)$ have higher BW on d 7 , 14, and 21 of the trial as compared with calves fed MR. Because most calves lost BW during the study, feed efficiency was not calculated.

Calves fed WM had higher $(P=0.04) \mathrm{DM}, \mathrm{CP}$, and ME intake with StDt between d 15 to 21 of the trial than those fed MR and MR+SB (Table 3). Addition of SB to MR did not affect StDt intake.

Calves selected more starter mixture from the StDt and avoided whole corn grain, especially in the first week of the trial (data not shown). Whole corn grain intake increased with calf age and its mean intake in the whole trial period amounted to $36 \%$ of StDt intake 
Table 3. Body weight, BW gain, ADG, DM, CP, and ME intake with starter diet (StDt) and health status of calves fed different liquid feeds

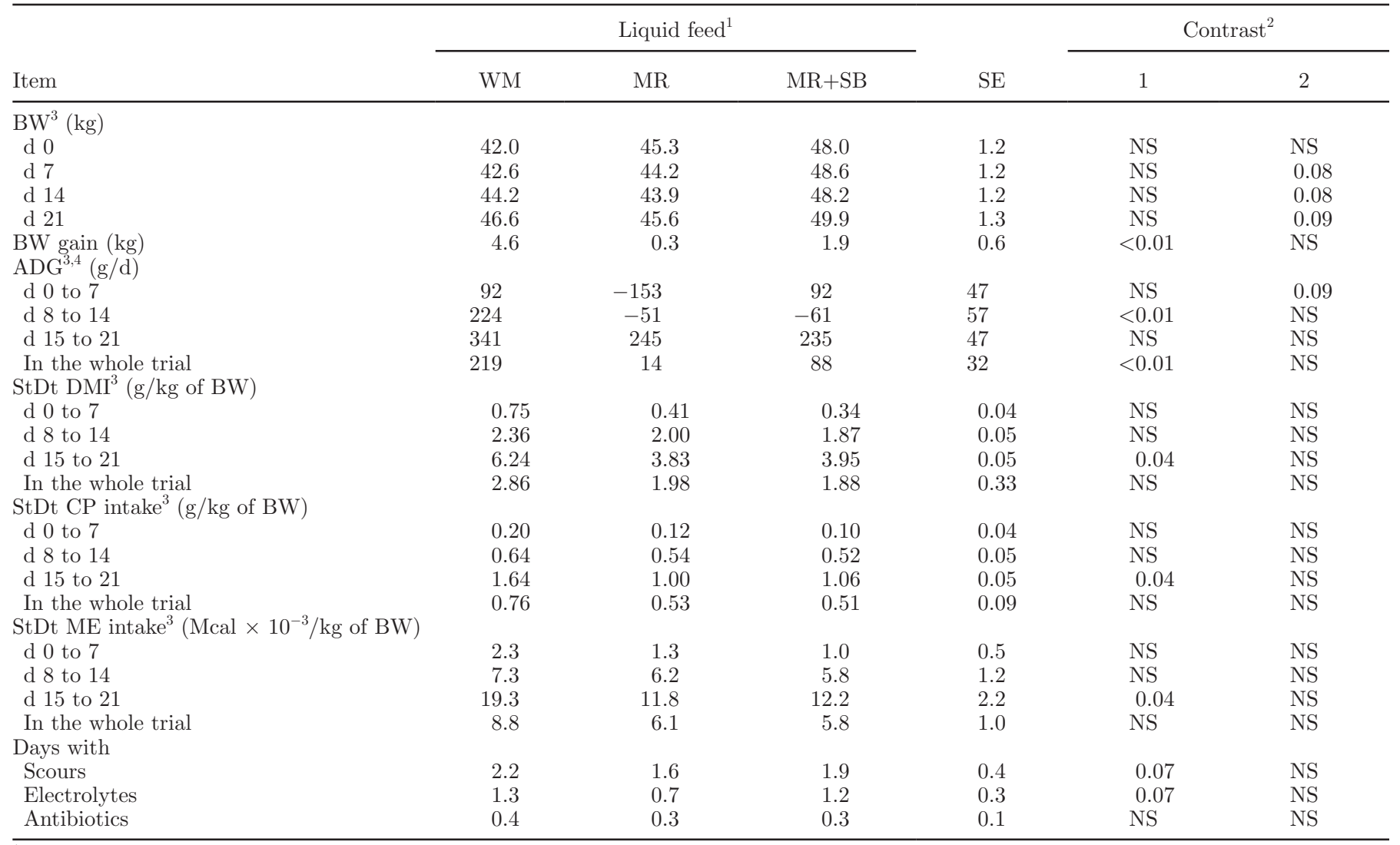

${ }^{1}$ Treatment: $\mathrm{WM}=$ whole milk; $\mathrm{MR}=$ milk replacer; $\mathrm{MR}+\mathrm{SB}=$ milk replacer containing $0.3 \%$ sodium butyrate.

${ }^{2} 1=\mathrm{WM}$ vs. MR and MR+SB; $2=\mathrm{MR}$ vs. MR+SB.

${ }^{3}$ Significant effect of time $(P<0.01)$

${ }^{4}$ Significant effect of liquid feed $(P=0.01)$.

(on feed basis). Whole corn grain intake was no different between treatments.

Calves were generally healthy during the trial and required only few medical interventions. Calves fed WM tended to $(P=0.07)$ have more days with scours and tended to $(P=0.07)$ require more electrolyte therapies as compared with calves fed MR and MR+SB (Table 3 ). No differences in health status between calves fed $\mathrm{MR}$ and $\mathrm{MR}+\mathrm{SB}$ were observed.

\section{Small Intestine Development}

Jejunum, ileum, and whole small intestine weights were lower $(P<0.05)$ in calves fed $\mathrm{MR}$ and $\mathrm{MR}+\mathrm{SB}$ as compared with calves fed WM (Table 4). Moreover, calves fed WM had a longer $(P=0.01)$ ileum as compared with those fed MR and MR+SB. Sodium butyrate supplementation in MR had no effect on small intestine weight and length or on weight and length of small intestine compartments.

Liquid feed had no effect on structural development of the jejunal wall apart from crypt depth, which was deeper $(P=0.01)$ in calves fed WM as compared with those fed MR and MR+SB (Table 4). Calves fed WM had a lower $(P=0.04)$ apoptotic index and tended to $(P=0.08)$ have a higher mitotic index in the middle jejunum as compared with calves fed milk replacers. Addition of SB into MR resulted in a higher $(P=0.01)$ mitotic index and lower $(P<0.01)$ apoptotic index.

Minor differences existed in brush border enzymes activities between treatments (data not presented). Calves fed WM had higher $(P=0.03)$ aminopeptidase $\mathrm{N}$ activity in the middle jejunum and tended to $(P=$ 0.08 ) have higher maltase activity in the distal jejunum as compared with calves fed MR and MR+SB. Addition of SB into MR tended to increase aminopeptidase A activity in the distal jejunum $(P=0.08)$. Sucrase activity was not detected.

\section{Rumen Development}

Total VFA concentration in the rumen fluid was lower $(P=0.05)$ in calves fed WM as compared with those fed MR and MR+SB (Table 5). It was particu- 
GÓRKA ET AL.

Table 4. Small intestine compartments weight and length, villus length, crypt depth, mucosa and muscularis thickness, and mitotic and apoptotic index in the middle jejunum of calves fed different liquid feeds

\begin{tabular}{|c|c|c|c|c|c|c|}
\hline \multirow[b]{2}{*}{ Item } & \multicolumn{3}{|c|}{ Liquid feed ${ }^{1}$} & \multirow[b]{2}{*}{$\mathrm{SE}$} & \multicolumn{2}{|c|}{ Contrast $^{2}$} \\
\hline & WM & MR & $\mathrm{MR}+\mathrm{SB}$ & & 1 & 2 \\
\hline \multicolumn{7}{|l|}{ Weight $(g)$} \\
\hline Whole small intestine & 1,382 & 1,102 & 1,244 & 45 & 0.01 & NS \\
\hline Duodenum & 58 & 55 & 59 & 2 & NS & NS \\
\hline Jejunum & 1,226 & 989 & 1,119 & 39 & 0.01 & NS \\
\hline Ileum & 99 & 68 & 66 & 7 & 0.05 & NS \\
\hline \multicolumn{7}{|l|}{ Length (m) } \\
\hline Whole small intestine & 13.5 & 13.8 & 12.4 & 0.38 & NS & NS \\
\hline Duodenum & 0.4 & 0.3 & 0.3 & 0.01 & NS & NS \\
\hline Jejunum & 12.6 & 13.1 & 11.8 & 0.38 & NS & NS \\
\hline Ileum & 0.6 & 0.4 & 0.4 & 0.04 & 0.01 & NS \\
\hline Villus length $(\mu \mathrm{m})$ & 437 & 392 & 393 & 19 & NS & NS \\
\hline Crypt depth $(\mu \mathrm{m})$ & 223 & 179 & 159 & 12 & 0.01 & NS \\
\hline Mucosa thickness $(\mu \mathrm{m})$ & 671 & 584 & 563 & 28 & NS & NS \\
\hline Muscularis thickness $(\mu \mathrm{m})$ & 355 & 340 & 323 & 13 & NS & NS \\
\hline Mitotic index (\%) & 5.0 & 3.0 & 4.8 & 0.3 & 0.08 & 0.01 \\
\hline Apoptotic index (\%) & 4.6 & 7.4 & 4.0 & 0.4 & 0.04 & $<0.01$ \\
\hline Mitosis/Apoptosis & 0.9 & 0.4 & 1.2 & 0.1 & NS & $<0.01$ \\
\hline
\end{tabular}

${ }^{1}$ Treatment: $\mathrm{WM}=$ whole milk; $\mathrm{MR}=$ milk replacer; $\mathrm{MR}+\mathrm{SB}=$ milk replacer containing $0.3 \%$ sodium butyrate.

${ }^{2} 1=\mathrm{WM}$ vs. $\mathrm{MR}$ and $\mathrm{MR}+\mathrm{SB} ; 2=\mathrm{MR}$ vs. MR+SB.

larly true for acetic and propionic acid. On the other hand, valeric acid concentration was higher $(P=0.02)$ in calves fed WM as compared with calves fed MR. No effect of liquid feed on $\mathrm{N}^{-\mathrm{NH}_{3}}$ concentration and $\mathrm{pH}$ was observed.

Calves fed WM had greater papillae length ( $P$ $<0.01)$ and papillae width $(P=0.05)$, and tended to $(P=0.06)$ have greater muscle layer thickness as compared with calves fed MR and MR+SB (Table 6). Reticulorumen weight, reticulorumen weight expressed as percent of whole stomach weight, and papillae length and width was higher $(P<0.05)$ in calves fed MR+SB as compared with those fed MR.

\section{Blood Parameters}

Calves fed WM had higher $(P<0.01)$ plasma glucose and urea concentrations in the whole trial period as compared with calves fed milk replacers (Table 7). On the other hand, plasma BHBA was lower $(P<0.01)$ on $\mathrm{d} 7$, and higher $(P=0.01)$ on $\mathrm{d} 21$ in calves fed WM. Calves fed $\mathrm{MR}+\mathrm{SB}$ tended to $(P<0.10)$ have higher plasma glucose concentration on $\mathrm{d} 7$ and 21 of the trial and had higher $(P<0.01)$ plasma glucose concentration in the whole trial period as compared with calves fed MR. No effect of SB supplementation in MR on plasma urea and BHBA were observed.

\section{Relationship Between Small Intestine and Rumen Development}

Significant Pearson correlations were found between small intestine and reticulorumen weights $(\mathrm{r}=0.47$, $P=0.03)$ as well as between activity of brush border lactase $(\mathrm{r}=0.56, P<0.01)$, maltase $(\mathrm{r}=0.44, P=$

Table 5. Parameters of rumen fermentation in calves fed different liquid feeds

\begin{tabular}{|c|c|c|c|c|c|c|}
\hline \multirow[b]{2}{*}{ Item } & \multicolumn{3}{|c|}{ Liquid feed $^{1}$} & \multirow[b]{2}{*}{$\mathrm{SE}$} & \multicolumn{2}{|c|}{ Contrast $^{2}$} \\
\hline & WM & $\mathrm{MR}$ & $\mathrm{MR}+\mathrm{SB}$ & & 1 & 2 \\
\hline $\mathrm{pH}$ & 5.2 & 5.3 & 5.3 & 0.1 & NS & NS \\
\hline Sum of VFA $(\mathrm{m} M / \mathrm{L})$ & 75.2 & 76.2 & 86.1 & 4.8 & 0.05 & NS \\
\hline Acetate $(\mathrm{m} M / \mathrm{L})$ & 31.6 & 38.1 & 41.0 & 2.4 & 0.05 & NS \\
\hline Propionate $(\mathrm{mM} / \mathrm{L})$ & 29.5 & 28.7 & 34.4 & 2.7 & 0.05 & NS \\
\hline Butyrate $(\mathrm{m} M / \mathrm{L})$ & 8.7 & 5.7 & 6.8 & 0.8 & NS & NS \\
\hline Valerate $(\mathrm{m} M / \mathrm{L})$ & 4.0 & 2.3 & 2.4 & 0.3 & 0.02 & NS \\
\hline Isobutyrate $(\mathrm{m} M / \mathrm{L})$ & 0.6 & 0.6 & 0.6 & 0.1 & NS & NS \\
\hline Isovalerate $(\mathrm{m} M / \mathrm{L})$ & 0.9 & 0.8 & 0.9 & 0.1 & NS & NS \\
\hline $\mathrm{N}-\mathrm{NH}_{3}(\mathrm{mg} \%)$ & 21.83 & 25.90 & 22.00 & 2.39 & NS & NS \\
\hline
\end{tabular}

${ }^{1}$ Treatment: $\mathrm{WM}=$ whole milk; $\mathrm{MR}=$ milk replacer; $\mathrm{MR}+\mathrm{SB}=$ milk replacer containing $0.3 \%$ sodium butyrate.

${ }^{2} 1=\mathrm{WM}$ vs. $\mathrm{MR}$ and $\mathrm{MR}+\mathrm{SB} ; 2=\mathrm{MR}$ vs. MR+SB. 
Table 6. Weight of stomach and stomach compartments, papillae length, papillae width, and tunica muscularis thickness from calves fed different liquid feeds

\begin{tabular}{|c|c|c|c|c|c|c|}
\hline \multirow[b]{2}{*}{ Item } & \multicolumn{3}{|c|}{ Liquid feed $^{1}$} & \multirow[b]{2}{*}{$\mathrm{SE}$} & \multicolumn{2}{|c|}{ Contrast $^{2}$} \\
\hline & WM & $\mathrm{MR}$ & $\mathrm{MR}+\mathrm{SB}$ & & 1 & 2 \\
\hline \multicolumn{7}{|l|}{ Weight (g) } \\
\hline Whole stomach & 774 & 622 & 730 & 38 & NS & NS \\
\hline Reticulorumen & 399 & 288 & 350 & 28 & NS & $<0.01$ \\
\hline Omasum & 78 & 79 & 82 & 4 & 0.04 & NS \\
\hline Abomasum & 297 & 296 & 298 & 10 & NS & NS \\
\hline \multicolumn{7}{|l|}{$\%$ of whole stomach weight } \\
\hline Reticulorumen & 50 & 43 & 47 & 1.4 & NS & 0.05 \\
\hline Omasum & 11 & 12 & 11 & 0.4 & 0.10 & NS \\
\hline Abomasum & 39 & 45 & 42 & 1.4 & NS & NS \\
\hline Papillae length ${ }^{3}(\mu \mathrm{m})$ & 527 & 314 & 443 & 27 & $<0.01$ & 0.02 \\
\hline Papillae width $^{3}(\mu \mathrm{m})$ & 191 & 150 & 186 & 7 & 0.05 & 0.03 \\
\hline Tunica muscularis $^{3}(\mu \mathrm{m})$ & 1,623 & 1,345 & 1,437 & 72 & 0.06 & NS \\
\hline
\end{tabular}

${ }^{1}$ Treatment: $\mathrm{WM}=$ whole milk; $\mathrm{MR}=$ milk replacer; $\mathrm{MR}+\mathrm{SB}=$ milk replacer containing $0.3 \%$ sodium butyrate.

${ }^{2} 1=\mathrm{WM}$ vs. $\mathrm{MR}$ and $\mathrm{MR}+\mathrm{SB} ; 2=\mathrm{MR}$ vs. $\mathrm{MR}+\mathrm{SB}$.

${ }^{3}$ Cranial dorsal sac.

0.05), aminopeptidase A $(\mathrm{r}=0.56, P<0.01)$, and aminopeptidase $\mathrm{N}(\mathrm{r}=0.46, P=0.04)$ and reticulorumen weight (Figure 1). On the other hand, jejunum length tended to correlate negatively $(\mathrm{r}=-0.39, P=0.08)$ with reticulorumen weight.

\section{DISCUSSION}

The results of this study show a negative effect of MR on small intestine development in calves, especially on maturation of intestinal epithelium, as indicated by a decrease of the mitosis/apoptosis index. Moreover, slower development of small intestine in calves fed milk replacers instead of WM indirectly slowed down rumen development. Acceleration of small intestine development in calves fed MR, in this study obtained by SB supplementation, positively affected rumen papillae development as well as reticulorumen weight. Furthermore, positive relationships between small intestine weight and reticulorumen weight as well as between ac-

Table 7. Blood parameters for calves fed different liquid feeds

\begin{tabular}{|c|c|c|c|c|c|c|}
\hline \multirow[b]{2}{*}{ Item } & \multicolumn{3}{|c|}{ Liquid feed $^{1}$} & \multirow[b]{2}{*}{$\mathrm{SE}$} & \multicolumn{2}{|c|}{ Contrast $^{2}$} \\
\hline & WM & $\mathrm{MR}$ & $\mathrm{MR}+\mathrm{SB}$ & & 1 & 2 \\
\hline \multicolumn{7}{|l|}{ Glucose $^{3}(\mathrm{mg} / \mathrm{dL})$} \\
\hline d 0 & 96.1 & 86.4 & 93.1 & 3.9 & NS & NS \\
\hline d 7 & 86.6 & 67.3 & 80.0 & 2.5 & 0.05 & 0.08 \\
\hline d 14 & 88.1 & 63.9 & 75.3 & 3.4 & $<0.01$ & NS \\
\hline d 21 & 89.6 & 63.0 & 75.0 & 3.2 & $<0.01$ & 0.10 \\
\hline In the whole trial & 90.1 & 70.2 & 81.1 & 2.7 & $<0.01$ & $<0.01$ \\
\hline \multicolumn{7}{|l|}{ Urea $^{3}$ (mg/dL) } \\
\hline d 0 & 17.6 & 18.0 & 17.7 & 1.3 & NS & NS \\
\hline d 7 & 27.9 & 20.8 & 19.2 & 1.6 & $<0.01$ & NS \\
\hline d 14 & 25.0 & 16.3 & 18.3 & 1.6 & $<0.01$ & NS \\
\hline d 21 & 28.0 & 19.7 & 19.3 & 1.4 & $<0.01$ & NS \\
\hline In the whole trial & 24.6 & 18.6 & 18.7 & 1.1 & $<0.01$ & NS \\
\hline \multicolumn{7}{|l|}{$\mathrm{BHBA}^{4}(\mathrm{~m} M / \mathrm{L})$} \\
\hline d 0 & 0.10 & 0.07 & 0.08 & 0.01 & NS & NS \\
\hline d 7 & 0.08 & 0.19 & 0.13 & 0.02 & $<0.01$ & NS \\
\hline d 14 & 0.15 & 0.10 & 0.07 & 0.02 & NS & NS \\
\hline d 21 & 0.17 & 0.06 & 0.07 & 0.02 & 0.01 & NS \\
\hline In the whole trial & 0.12 & 0.10 & 0.09 & 0.01 & NS & NS \\
\hline
\end{tabular}

${ }^{1}$ Treatment: $\mathrm{WM}=$ whole milk; $\mathrm{MR}=$ milk replacer; $\mathrm{MR}+\mathrm{SB}=$ milk replacer containing $0.3 \%$ sodium butyrate.

${ }^{2} 1=\mathrm{WM}$ vs. $\mathrm{MR}$ and $\mathrm{MR}+\mathrm{SB} ; 2=\mathrm{MR}$ vs. $\mathrm{MR}+\mathrm{SB}$.

${ }^{3}$ Significant effect of liquid feed $(P<0.01)$ and time $(P<0.01)$.

${ }^{4}$ Significant effect of interaction of liquid feed $\times$ time $(P<0.01)$. 

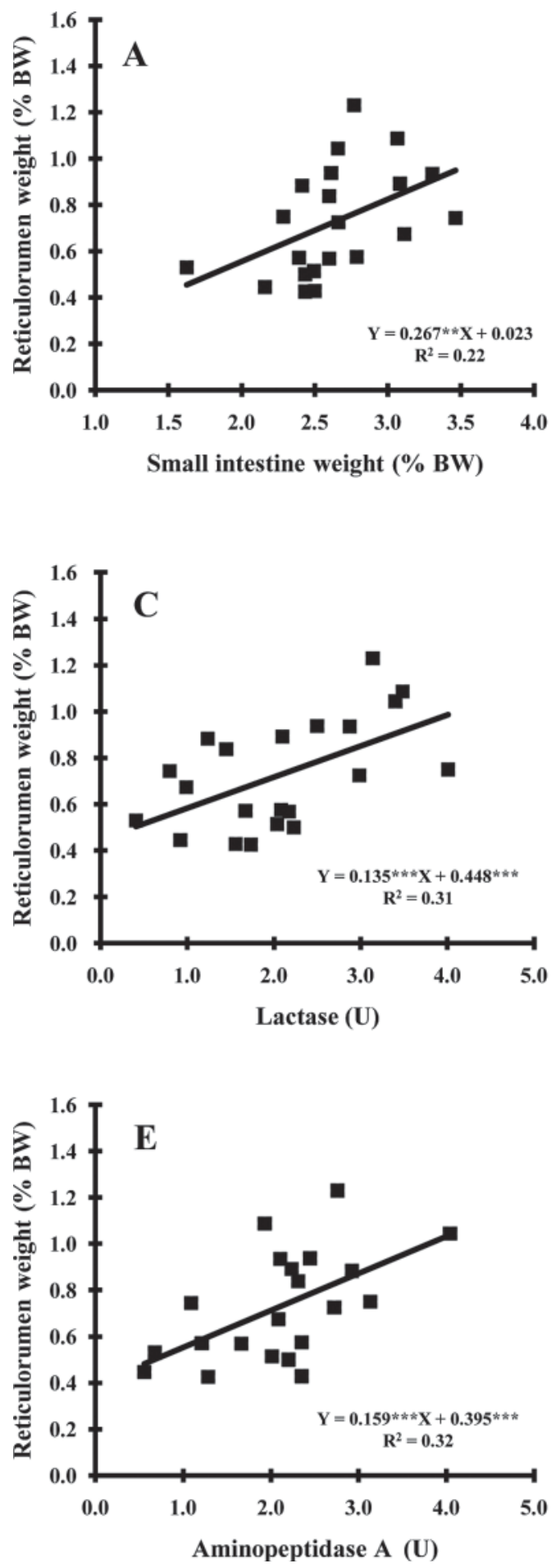
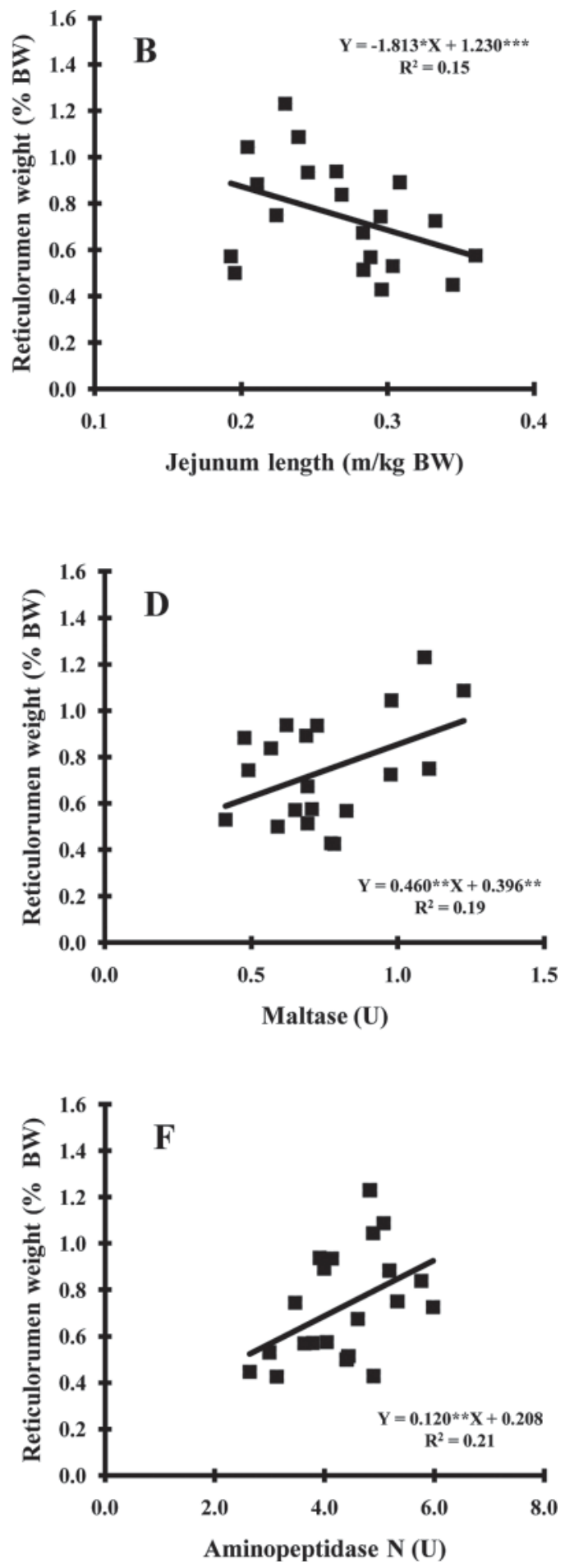

Figure 1. Relationship between reticulorumen weight and small intestine weight (A), jejunum length (B), lactase (C), maltase (D), aminopeptidase A (E), and aminopeptidase $\mathrm{N}(\mathrm{F})$ activity. ${ }^{*} P<0.10 ; * * P<0.05 ;{ }^{* * *} P<0.01$.

tivity of most of the investigated brush border enzymes and reticulorumen weight were found. This indicates that not only solid feed composition, solid feed structure, or liquid feed intake as it is widely accepted, but also liquid feed type and composition may affect rumen development indirectly by modulation of small intestine development.

Negative effects of feeding calves MR on small intestine development have been shown (Seegraber and Morrill, 1986; Montagne et al., 1999; Blättler et al., 2001). 
These effects are mainly manifested by a decrease of the proliferative potential of intestinal epithelium and an increase in the number of enterocytes that undergo apoptosis and, in consequence, by a decrease in villus height, crypt depth, brush border enzymes activity, and efficiency of nutrient absorption (Seegraber and Morrill, 1986; Montagne et al., 1999; Blättler et al., 2001). Some of these unfavorable consequences were confirmed in this study. Calves fed MR had significantly lower crypt depth and tendencies toward lower mitotic index of the small intestine epithelium were found, indicating decreased proliferative potential. A higher apoptotic index of the intestinal epithelium in calves fed MR and lower aminopeptidase $\mathrm{N}$ activity in the middle jejunum were also shown. Moreover, calves fed MR had significantly lower small intestine weight as compared with calves fed WM, which unambiguously confirms slower small intestine development in calves fed milk substitutes.

Sodium butyrate was previously shown to have a positive effect on small intestine development in newborn calves and other mammal species that were fed MR (Kotunia et al., 2004; Pietrzak et al., 2008; Guilloteau et al., 2009) and such an effect was also shown in this study. This positive effect of SB supplementation on small intestine development was demonstrated mainly by faster maturation of the intestinal epithelium, illustrated by a decrease of the mitosis/apoptosis index, which was similar in calves fed either MR+SB or WM. However, although addition of SB to MR significantly increased the mitotic and decreased the apoptotic index of the small intestine epithelium, it did not fully prevent negative effects of feeding calves MR instead of WM on the small intestine development. Sodium butyrate supplementation had no effect on whole small intestine weight and crypt depth, which were higher in calves fed WM. The negative effect of MR on intestinal epithelium development is especially pronounced when MR contains soy proteins, as was the case in this study, and such an effect is especially difficult to eliminate (Grant et al., 1989; Montagne et al., 1999; Drackley et al., 2006). Similarly Guilloteau et al. (2009) observed no effect of presence of SB in MR that contained soy proteins on the dimension of the small intestine and villus height in veal calves. Moreover, these authors noticed even a decrease of crypt depth in the middle jejunum as a result of SB supplementation.

Although addition of SB in MR was unable to fully prevent the negative effects of feeding calves MR on small intestine development, its effect was sufficient for acceleration of reticulorumen weight and rumen papillae development. This fact, together with significant positive correlations between small intestine weight and reticulorumen weight, as well as between activity of most of the investigated brush border enzymes and reticulorumen weight, supports the importance of liquid feed composition for forestomach development. However, faster rumen development in calves fed $\mathrm{MR}+\mathrm{SB}$ as compared with those fed MR was observed despite a lack of differences in solid feed intake between these treatments. Because solid feed intake is considered as the main stimulator of rumen development (Tamate et al., 1962; Žitňan et al., 1998; Lesmeister and Heinrichs, 2004), it indicates the importance of other mechanisms of liquid feed action on forestomach development. Nevertheless, calves fed MR+SB had about 25\% higher StDt intake in the last period of the trial (d 15 to 21; data not shown) as compared with those fed MR, and StDt intake was positively correlated with reticulorumen weight in this study $(\mathrm{r}=0.97, P<0.01)$. Therefore, it seems that the slaughter age of calves coincided with the period in which an effect of addition of SB to $\mathrm{MR}$ on StDt intake began to take place and long-term effects of SB on calf gastrointestinal tract development should be considered.

Gastrointestinal tract development requires an adequate supply of nutrients. Glucose is the main source of energy for proliferated rumen epithelial cells (Giesecke et al., 1985; Baldwin and Jesse, 1992) and its concentration in plasma was higher in calves fed $\mathrm{MR}+\mathrm{SB}$ as compared with those fed MR. Additionally, plasma glucose concentration in this study correlated positively with reticulorumen weight $(\mathrm{r}=0.59, P<0.01)$ and papillae length $(\mathrm{r}=0.68, P<0.01)$. Improvement of intestinal digestion efficiency resulting from enhanced pancreatic exocrine secretion and brush border enzymes activity (Guilloteau et al., 2004, 2009, 2010) could be a reason for higher plasma glucose concentration and faster rumen development in calves fed MR+SB. Accessibility of nutrients, as affected by digestion efficiency in calves fed MR+SB, could also prevent BW loss, which was observed in calves fed MR. Body weight loss is often observed in the first weeks after MR implementation to the diet of newborn calves (Seegraber and Morrill, 1986; Cruywagen et al., 1996; Galvão et al., 2005). In many cases, higher ADG and BW of calves coincided with higher papillae length (Anderson et al., 1982; Lesmeister et al., 2004; Khan et al., 2007a). Therefore, optimization of MR composition for better nutrient utilization could be one of the ways of rumen development stimulation in calves.

In this study, MR containing soy protein was used to ensure slower small intestine development in calves fed MR. Such a methodological concept allowed us to determine whether any relationship between small intestine and rumen development exists during the first weeks of calf life. The results suggest a need for further verification of the proposed hypothesis. The effect of 
higher $\mathrm{CP}$ and ME intake in the group of calves fed WM as compared with the group of calves fed MR on gastrointestinal tract development should also be considered.

In the present study, calves fed WM had significantly lower VFA concentrations in the rumen fluid, particularly acetic and propionic acid, as compared with calves fed MR. Together with higher StDt intake in this group of calves, such an observation suggests more efficient VFA absorption. Additionally, plasma BHBA concentration, a widely accepted marker of development of rumen metabolic function (Quigley et al., 1991; Klotz and Heitmann, 2007; Kristensen et al., 2007), showed a normal gradual increase with age only in calves fed WM. Calves fed WM had also higher valeric acid concentration in the rumen fluid as compared with those fed MR. Our results partially correspond with those presented by Niwińska and Strzetelski (2005) who showed a tendency toward lower VFA concentrations in the rumen fluid of newborn calves fed WM. Among VFA produced in the rumen, butyric and valeric acids are preferred sources of energy for rumen epithelium cells (Kristensen et al., 2000; Kristensen and Harmon, 2004). However, based on results obtained in this study and the study of Niwińska and Strzetelski (2005), it seems not true for newborn calves fed WM, a liquid feed that ensures optimal gastrointestinal tract development. Higher valeric acid concentrations in this study and higher butyric acid concentrations in the study of Niwińska and Strzetelski (2005) in the rumen fluid of calves fed WM as compared with those fed MR may indicate their lower absorption and utilization. Addition of SB to MR, at least in the concentration used in this study, seems to have a minor effect on VFA absorption and VFA metabolism by rumen epithelium cells.

\section{CONCLUSIONS}

Feeding calves MR containing soy protein instead of WM slows down small intestine development, negatively affects growth and metabolic status of animals, and indirectly slows down rumen development. Addition of SB into MR stimulates small intestine development and partially eliminates the negative effects of MR on rumen development. The results of this study show that rumen development may be affected by liquid feed type and composition.

\section{ACKNOWLEDGMENTS}

This study was funded by the Ministry of Science and Higher Education of Poland (Grant no. 1164/ P01/2006/31 and 3196/B/P01/35), and partially by European Social Funds and National Budget of Poland.
The authors acknowledge the Top Farms Głubczyce (Głubczyce, Poland) staff for help in collecting data and The Kielanowski Institute of Animal Physiology and Nutrition (Jabłonna, Poland), especially Jarosław Woliński, for giving access to the laboratory and laboratory assistance.

\section{REFERENCES}

Anderson, M. J., M. Khoyloo, and J. L. Walters. 1982. Effect of feeding whole cottonseed on intake, body weight, and reticulorumen development of young Holstein calves. J. Dairy Sci. 65:764-772.

AOAC. 2000. Official Methods of Analysis. 17th ed. Association of Official Analytical Chemists, Washington, DC.

Baldwin, R. L. VI, and B. W. Jesse. 1992. Developmental changes in glucose and butyrate metabolism by isolated sheep ruminal cells. J. Nutr. 122:1149-1153.

Baldwin, R. L. VI, K. R. McLeod, J. L. Klotz, and R. N. Heitmann. 2004. Rumen development, intestinal growth and hepatic metabolism in the pre- and postweaning ruminant. J. Dairy Sci. 87(E. Suppl.):E55-E65.

Baumrucker, C. R., and J. W. Blum. 1994. Effects of dietary recombinant human insulin-like growth factor-I on concentrations of hormones and growth factors in the blood of newborn calves. J. Endocrinol. 140:15-21.

Blättler, U., H. M. Hammon, C. Morel, C. Philipona, A. Rauprich, V. Romé, I. Le Huërou-Luron, P. Guilloteau, and J. W. Blum. 2001 Feeding colostrum, its composition and feeding duration variably modify proliferation and morphology of the intestine and digestive enzyme activities of neonatal calves. J. Nutr. 131:1256-1263.

Conway, E. J. 1962. Ammonia. General method. Page 98-100 in Microdiffusion Analysis and Volumetric Error. Crosby Lockwood and Son Ltd., London, UK.

Cruywagen, C. W., I. Jordaan, and L. Venter. 1996. Effect of Lactobacillus acidophilus supplementation of milk replacer on preweaning performance of calves. J. Dairy Sci. 79:483-486.

Dahlqvist, A. 1984. Assay of intestinal disaccharidases. Scand. J. of Clin. Lab. Invest. 44:169-172.

Drackley, J. K., R. M. Blome, K. S. Bartlett, and K. L. Bailey. 2006. Supplementation of $1 \%$ L-glutamine to milk replacer does not overcome the growth depression in calves caused by soy protein concentrate. J. Dairy Sci. 89:1688-1693.

Erwin, E. S., G. J. Marco, and E. M. Emery. 1961. Volatile fatty acid analyses of blood and rumen fluid by gas chromatography. J. Dairy Sci. 44:1768-1771.

Faisant, N., V. Planchot, F. Kozlowski, M. Pacouret, P. Colonna, and M. Champ. 1995. Resistant starch determination adapted to products containing high level of resistant starch. Sci. Alim. 15:83-89.

Galvão, K. N., J. E. P. Santos, A. Coscioni, M. Villaseñor, W. M. Sischo, and A. C. B. Berge. 2005. Effect of feeding live yeast products to calves with failure of passive transfer on performance and patterns of antibiotic resistance in fecal Escherichia coli. Reprod. Nutr. Dev. 45:427-440.

Giesecke, D., U. Beck, and B. Emmanuel. 1985. Ketogenic regulation by certain metabolites in rumen epithelium. Comp. Biochem. Physiol. B 81:863-867.

Godlewski, M. M., J. Bierła, A. Strzałkowski, D. Martinez-Puig, B. Pająk, A. Kotunia, C. Chetrit, and R. Zabielski. 2009. A novel cytometric approach to study intestinal mucosa rebuilding in weaned pigs fed with dietary nucleotides. Livest. Sci. 123:215-220.

Grant, A. L., R. E. Holland, J. W. Thomas, K. J. King, and J. S. Liesman. 1989. Effects of dietary amines on the small intestine in calves fed soybean protein. J. Nutr. 119:1034-1041.

Guilloteau, P., V. Romé, L. Le Normand, G. Savary, and R. Zabielski. 2004. Is Na-butyrate a growth factor in the preruminant calf? Preliminary results. J. Anim. Feed Sci. 13(Suppl. 1):393-396.

Guilloteau, P., G. Savary, Y. Jaguelin-Peyrault, V. Romé, L. Le Normand, and R. Zabielski. 2010. Dietary sodium-butyrate supplementation increases digestibility and pancreatic secretion in young milk fed calves. J. Dairy Sci. 93:5842-5850. 
Guilloteau, P., R. Zabielski, J. C. David, J. W. Blum, J. A. Morisset, M. Biernat, J. Woliński, D. Laubitz, and Y. Hamon. 2009. Sodiumbutyrate as a growth promoter in milk replacer formula for young calves. J. Dairy Sci. 92:1038-1049.

Hartree, E. F. 1972. Determination of protein: A modification of the Lowry method that gives a linear photometric response. Anal. Biochem. 48:422-427.

Hill, T. M., J. M. Aldrich, R. L. Schlotterbeck, and H. G. Bateman II. 2007. Effects of changing the fat and fatty acid composition of milk replacers fed to neonatal calves. Prof. Anim. Sci. 23:135-143.

Hill, T. M., H. G. Bateman II, J. M. Aldrich, and R. L. Schlotterbeck. 2008. Effect of feeding different carbohydrate sources and amounts to young calves. J. Dairy Sci. 91:3128-3137.

Khan, M. A., H. J. Lee, W. S. Lee, H. S. Kim, K. S. Ki, T. Y. Hur, G. H. Suh, S. J. Kang, and Y. J. Choi. 2007a. Structural growth, rumen development, and metabolic and immune responses of Holstein male calves fed milk through step-down and conventional methods. J. Dairy Sci. 90:3376-3387.

Khan, M. A., H. J. Lee, W. S. Lee, H. S. Kim, S. B. Kim, K. S. Ki, S J. Park, J. K. Ha, and Y. J. Choi. 2007b. Starch source evaluation in calf starter: I. Feed consumption, body weight gain, structural growth, and blood metabolites in Holstein calves. J. Dairy Sci. 90:5259-5268

Klotz, J. L., and R. N. Heitmann. 2007. Changes in net portal nutrient flux in response to weaning transition and ionophore supplementation in dairy calves. J. Dairy Sci. 90:1326-1339.

Kotunia, A., J. Woliński, D. Laubitz, M. Jurkowska, V. Romé, P. Guilloteau, and R. Zabielski. 2004. Effect of sodium butyrate on the small intestine development in neonatal piglets fed by artificial sow. J. Physiol. Pharmacol. 55(Suppl. 2):59-68.

Kristensen, N. B., and D. L. Harmon. 2004. Effect of increasing ruminal butyrate absorption on splanchnic metabolism of volatile fatty acids absorbed from the washed reticulorumen of steers. J. Anim. Sci. 82:3549-3559.

Kristensen, N. B., S. G. Pierzynowski, and A. Danfaer. 2000. Net portal appearance of volatile fatty acids in sheep intraruminally infused with mixtures of acetate, propionate, isobutyrate, butyrate, and valerate. J. Anim. Sci. 78:1372-1379.

Kristensen, N. B., J. Sehested, S. K. Jensen, and M. Vestergaard. 2007. Effect of milk allowance on concentrate intake, ruminal environment, and ruminal development in milk-fed Holstein calves. J. Dairy Sci. 90:4346-4355

Kuhne, S., H. M. Hammon, R. M. Bruckmaier, C. Morel, Y. Zbinden, and J. W. Blum. 2000. Growth performance, metabolic and endocrine traits, and absorptive capacity in neonatal calves fed either colostrum or milk replacer at two levels. J. Anim. Sci. 78:609-620.

Larson, L. L., F. G. Owen, J. L. Albright, R. D. Appleman, R. C. Lamb, and L. D. Muller. 1977. Guidelines toward more uniformity in measuring and reporting calf experimental data. J. Dairy Sci. 60:989-991.

Lesmeister, K. E., and A. J. Heinrichs. 2004. Effects of corn processing on growth characteristics, rumen development, and rumen parameters in neonatal dairy calves. J. Dairy Sci. 87:3439-3450.

Lesmeister, K. E., A. J. Heinrichs, and M. T. Gabler. 2004. Effects of supplemental yeast (Saccharomyces cerevisiae) culture on rumen development, growth characteristics, and blood parameters in neonatal dairy calves. J. Dairy Sci. 87:1832-1839.

Littell, R. C., P. R. Henry, and C. B. Ammerman. 1998. Statistical analysis of repeated measures data using SAS procedures. J. Anim. Sci. 76:1216-1231.

Maroux, S., D. Louvard, and J. Baratti. 1973. The aminopeptidase from hog intestinal brush border. Biochim. Biophys. Acta 321:282-295.

Montagne, L., R. Toullec, T. Savidge, and J.-P. Lallès. 1999. Morphology and enzyme activities of the small intestine are modulated by dietary protein source in the preruminant calf. Reprod. Nutr. Dev. 39:455-466.

Nagatsu, T., M. Hino, H. Fuyamada, H. Hayakawa, T. Sakakibara, Y. Nakagawa, and T. Takemoto. 1976. New chromogenic substrates for X-propyl dipeptidyl-aminopeptidase. Anal. Biochem. 74:466476

Niwińska, B., and J. Strzetelski. 2005. Effects of type of liquid feed and feeding frequency on rumen development and rearing performance of calves. Ann. Anim. Sci. 5:125-134.

NRC. 2001. Nutrient Requirements of Dairy Cattle. National Academy Press, Washington, DC.

Pietrzak, P., A. Kotunia, J. Wrzesińska, P. Górka, J. Bierła, Z. M. Kowalski, and R. Zabielski. 2008. Dietary sodium butyrate stimulates rebuilding of small intestinal epithelium in neonatal calves. Folia Histochem. Cytobiol. 46(Suppl. 2):S65.

Quigley, J. D., III, L. A. Caldwell, G. D. Sinks, and R. N. Heitmann. 1991. Changes in blood glucose, nonesterified fatty acids, and ketones in response to weaning and feed intake in young calves. J. Dairy Sci. 74:250-257.

Sakata, T., K. Hikosaka, Y. Shiomura, and H. Tamate. 1980. Stimulatory effect of insulin on ruminal epithelium cell mitosis in adult sheep. Br. J. Nutr. 44:325-331.

SAS. 2002. SAS User's Guide: Statistics. Version 9.1. SAS Institute Inc., Cary, NC.

Seegraber, F. J., and J. L. Morrill. 1986. Effect of protein source in calf milk replacers on morphology and absorptive ability of small intestine. J. Dairy Sci. 69:460-469.

Tamate, H., A. D. McGilliard, N. L. Jacobson, and R. Getty. 1962. Effect of various dietaries on the anatomical development of the stomach in the calf. J. Dairy Sci. 45:408-420.

Zabielski, R., C. Dardillat, I. Le Huërou-Luron, C. Bernard, J. A Chayvialle, and P. Guilloteau. 1998. Periodic fluctuations of gut regulatory peptides in phase with the duodenal migrating myoelectric complex in preruminant calves: Effect of different sources of dietary protein. Br. J. Nutr. 79:287-296.

Zitnan, R., S. Kuhla, P. Sanftleben, A. Bliska, F. Schneider, M. Zupcanova, and J. Voigt. 2005. Diet induced ruminal papillae development in neonatal calves not correlating with rumen butyrate. Vet. Med. - Czech. 50:472-479.

Žitňan, R., J. Voigt, U. Schönhusen, J. Wegner, M. Kokardová, H Hagemeister, M. Levkut, S. Kuhla, and A. Sommer. 1998. Influence of dietary concentrate to forage ratio on the development of rumen mucosa in calves. Arch. Anim. Nutr. 51:279-291. 